\title{
Reimbursement in Endoscopy: How Can New Procedures Be Implemented?
}

\author{
Michael-Holger Wilke Markus Rathmayer \\ inspiring-health - Dr. Wilke GmbH, Munich, Germany
}

\section{Keywords}

Diagnosis-related groups · Gastroenterology ·

Endoscopy - NUB · Innovation funding · Cost allocation . Institute for Remuneration Systems in Hospitals (InEK)

while the endoluminal conduit for the treatment of type 2 diabetes was established as NUB payment.

(c) 2016 S. Karger GmbH, Freiburg

\section{Summary}

Background: New procedures in endoscopy take time to be incorporated in the German diagnosis-related groups (DRG) system. Depending on the extent of innovation and the costs, several pathways are possible. Methods: This article provides an overview of possible pathways to implement new procedures in the German DRG payment system. Additionally, we compare the results of 2 surveys on the system of New Diagnostic and Treatment Methods (Neue Untersuchungs- und Behandlungsmethoden; NUB). Furthermore, the pathways of 2 innovations in endoscopy are described in detail and compared with the possibilities within the legal framework. Results: The different pathways like NUB applications or DRG change requests and the underlying legal framework are described in detail. The results of a survey from 2007 on the daily practice of NUB funding in Germany show that the extent of innovations which receive a positive assessment (status 1 ) is $46 \%$ compared to $43.7 \%$ in a survey from 2007 , and that $77 \%$ of the status 1 procedures (and drugs) can be negotiated into a payment - compared to $53 \%$ in the older survey. Conclusion: Medical scientific societies should be involved in this process from the beginning. Besides the importance for the hospital application process $(81.3 \%$ of all medical controllers want to have society support), the regulatory bodies (e.g. DIMDI, InEK, G-BA) also appreciate scientific statements. Two examples show the pathways in detail. For radiofrequency ablation of Barrett's esophagus, the pathway of continuous change requests was chosen,

\section{Introduction}

Healthcare spending in Germany accounts for approximately $11 \%$ of the gross domestic product (GDP). The mandatory health insurance (Gesetzliche Krankenversicherung; GKV) covers about 92\% of the population. In 2014, EUR 193.63 billion were spent, of which EUR 68 billion were expenditures for hospitals and EUR 33 billion were payments for outpatient services provided by doctors. German hospitals are reimbursed by a per-case payment system based on the so-called diagnosis-related groups (DRG), where the principal diagnosis, the procedures, and to some extent the comorbidities and complications during hospital stay determine the payment. In 2013, 19.2 million inpatient cases were treated in German hospitals (including 1-day cases reimbursed via DRG), of which 1.9 million were admitted having a principle diagnosis of a digestive disease [1].

Gastroenterology, and in particular endoscopy, is a field with frequently occurring innovations, involving either the optimization of existing technologies, like better endoscopes or digital imaging, or the introduction of new approaches such as the swallowable endoscopic micro camera, the use of radiofrequency ablation (RFA) in the treatment of Barrett's esophagus, or EndoBarrier ${ }^{\circledR}$ (GI Dynamics, Inc., Lexington, MA, USA) for the treatment of type 2 diabetes.

This article will give an overview of the basic principles for new procedures to be included in the German DRG (G-DRG) system and the existing and upcoming regulatory framework for innovation funding, and will provide a sample pathway for the successful implementation of new endoscopic procedures in the system. Finally, we will give a brief overview of the results of a survey on innovation funding conducted by our institution in May 2015. 
Table 1. Extract from G-DRG $\$ 21$ browser with top-10 procedures covered by DRG G46B

\begin{tabular}{|c|c|c|c|}
\hline DRG & Code & Text & Cases, $\mathrm{n}$ \\
\hline G46B & $1-632$ & diagnostic esophagogastroduodenoscopy & 16,128 \\
\hline G46B & 8-800.c0 & $\begin{array}{l}\text { transfusion of whole blood, packed red blood cells, and platelet concentrates; } \\
\text { packed red blood cells: } 1 \text { to less than } 6 \text { units }\end{array}$ & 7,576 \\
\hline G46B & 1-440.a & $\begin{array}{l}\text { endoscopic biopsy of the upper digestive tract, bile ducts, and pancreas: } \\
1-5 \text { biopsies along the upper digestive tract }\end{array}$ & 6,120 \\
\hline G46B & $8-930$ & $\begin{array}{l}\text { monitoring of respiratory, cardiac, and circulatory function without measurement } \\
\text { of pulmonary arterial pressure and central venous pressure }\end{array}$ & 4,120 \\
\hline G46B & $3-225$ & abdominal computed tomography scan with contrast medium & 3,575 \\
\hline G46B & $3-222$ & computed tomography scan of the chest with contrast medium & 2,500 \\
\hline G46B & $1-650.1$ & diagnostic colonoscopy: total, to the cecum & 1,928 \\
\hline G46B & $5-449 . \mathrm{d} 3$ & other operations on stomach: clipping - endoscopic & 1,926 \\
\hline G46B & $5-449 . e 3$ & other operations on stomach: injection - endoscopic & 1,912 \\
\hline G46B & $1-440.9$ & $\begin{array}{l}\text { endoscopic biopsy of the upper digestive tract, bile ducts, and pancreas: } \\
\text { stage biopsy along the upper digestive tract }\end{array}$ & 1,810 \\
\hline G46B & $1-650.2$ & diagnostic colonoscopy: total, with ileoscopy & 1,804 \\
\hline G46B & $3-990$ & computerized image analysis with 3D evaluation & 1,574 \\
\hline G46B & $3-200$ & native computed tomography of the skull & 1,373 \\
\hline G46B & $8-900$ & intravenous anesthesia & 1,362 \\
\hline G46B & $8-980.0$ & complex intensive care treatment (basic procedure): $1-184$ effort points & 1,285 \\
\hline G46B & $8-800 . c 1$ & $\begin{array}{l}\text { transfusion of whole blood, packed red blood cells, and platelet concentrates; } \\
\text { packed red blood cells: } 6 \text { to under } 11 \text { units }\end{array}$ & 1,139 \\
\hline G46B & $3-226$ & computed tomography of the pelvis with contrast medium & 1,113 \\
\hline G46B & $8-831.0$ & insertion and changing of central venous catheter tubes: placement & 1,101 \\
\hline G46B & $1-444.7$ & endoscopic biopsy along the lower digestive tract: $1-5$ biopsies & 1,031 \\
\hline G46B & $5-469 . e 3$ & other operations on intestine: injection - endoscopic & 1,020 \\
\hline
\end{tabular}

\section{Basic Principles}

In the German healthcare law (Sozialgesetzbuch; SGB V), there are 2 very different basic principles for new diagnostic and treatment methods concerning universal coverage by the GKV system, depending on whether the procedure is an outpatient or inpatient (hospital) treatment (fig. 1).

The federal joint committee (Gemeinsamer Bundesausschuss; G-BA) issues permission for coverage in the outpatient setting and the prohibition of coverage in the inpatient setting.

This article focusses on coverage in the inpatient (hospital) setting, as the outpatient setting has less clear rules and pathways compared to the hospital system.

As the DRG system uses procedure codes (so-called Operationen- und Prozedurenschlüssel or OPS, maintained by DIMDI, the German Institute for Medical Documentation and Information), every new procedure that is different from existing procedures needs a new OPS code to describe it. DIMDI accepts applications for new procedures from medical scientific societies. These applications require a special form and are due on February 28 of every year. The

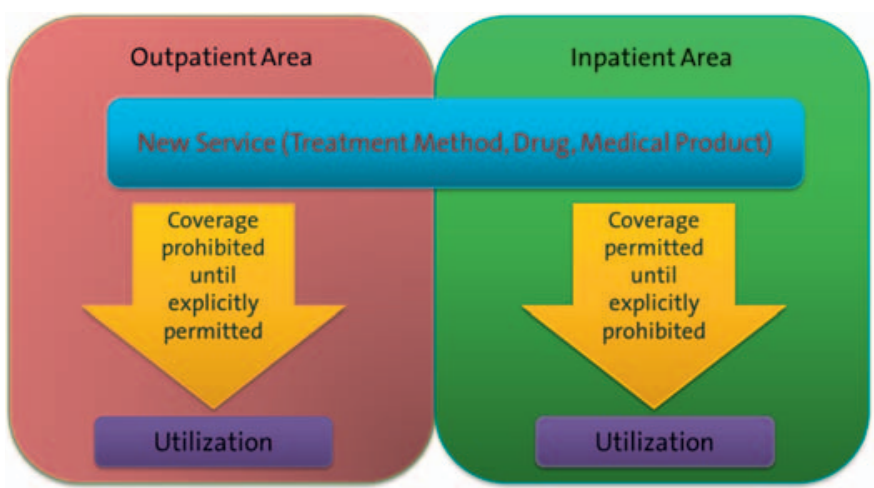

Fig. 1. Difference concerning coverage between inpatient and outpatient area.

new OPS classification is usually published in August. With this publication, applicants find out if their proposal was accepted.

Within every DRG, especially in endoscopy, a multitude of different procedures are covered (table 1). As long as procedures cause similar average resource consumption, they are supposed to be sufficiently reimbursed via a specific DRG. 
Every new procedure - whether or not an OPS code has already been issues - is examined by determining the DRG it most likely will be assigned to. After determining the DRG, the average overall resource consumption (i.e. costs) in this DRG is compared to the average overall costs using the new procedure. In this comparison, all costs are taken into account. If a new procedure is more costly but the patient spends less time in hospital, it is possible that the existing DRG already covers the new treatment. This analysis is called 'differential cost calculation'. Depending on the result of this analysis, there are 3 major funding pathways for the implementation of new procedures in the DRG system:

Pathway A: If a new procedure is already covered by an existing DRG, clinicians are free to use it; the OPS code is important for further development.

Pathway B: If a new procedure is not covered (i.e., costs exceed EUR 1,000.00 or even the standard deviation of the DRG), an application for funding through the system of New Diagnostic and Treatment Methods (Neue Untersuchungs- und Behandlungsmethoden; NUB) is possible.

Pathway C: If DRG coverage is not sufficient and NUB is not possible or has been rejected, medical scientific societies can apply for a change in DRG assignment.

\section{Regulatory Framework for NUB}

NUB is a temporary payment designed to bridge the gap until new procedures are fully included in the DRG reimbursement system. The hospital remuneration law (Krankenhausentgeltgesetz; KHEntgG) states in $\$ 6$, paragraph 2 [2]: 'New diagnostic and therapeutic methods that are not yet covered by the DRG reimbursement system can be temporarily reimbursed by extra payments on top of the DRGs'. Hospitals have to apply for NUB funding to the Institute for the Hospital Remuneration System (Institut für das Entgeltsystem im Krankenhaus; InEK), where the coverage and eligibility of the methods will be examined. The date for application is October 31, and the InEK will publish the results of the assessment by January 31 of the following year. The NUB assessment can result in 4 different statuses (table 2) [3].

Once the status is published, hospitals can negotiate the NUB payments with the insurance companies.

The German Society for Gastroenterology, Digestive, and Metabolic Diseases (Deutsche Gesellschaft für Gastroenterologie, Verdauungs- und Stoffwechselkrankheiten; DGVS) have published the results for all previous NUB applications (2009-2015) which they supported by providing templates on their website [4]. We divided them into drugs and interventions in visceral medicine and summarized the results for the interventions. The analysis shows that 4 procedures out of a total of 17 applications were approved (NUB status 1), all others were rejected (status 2) (table 3).

Very often, applicants are surprised or do not understand why a given method has not obtained status 1 . In their selection process, InEK applies the following criteria:
Table 2. Status of NUB application by InEK published at the end of January each year

\begin{tabular}{ll}
\hline Status by InEK & Description \\
\hline 1 & $\begin{array}{l}\text { method fulfils the criteria for NUB and payment } \\
\text { shall be negotiated }\end{array}$ \\
\hline 3 & $\begin{array}{l}\text { method does not fulfil the criteria and no payment } \\
\text { possible }\end{array}$ \\
\hline 4 & InEK was not able to complete assessment in due time \\
\hline $\begin{array}{l}\text { the content of the application was not understandable } \\
\text { to the InEK } \rightarrow \text { method seems to be an innovation but e.g. } \\
\text { the costs were not sufficiently explained; for methods with } \\
\text { status } 4 \text {, hospitals and insurances can negotiate a payment } \\
\text { if an agreement is reached }\end{array}$ \\
\hline
\end{tabular}

Table 3. Overview of methods and statuses from DGVS-supported NUB

\begin{tabular}{ll}
\hline Procedure & Approved \\
\hline Gastric pacer & yes \\
Ascites pump (peritoneal-vesical) & yes \\
Endoluminal fundoplication & no \\
Radiofrequency ablation of Barrett's esophagus & no \\
Measuring liver vein occlusion pressure & no \\
Endoscopic submucosal dissection (ESD) & no \\
Esophageal impedance measurement & no \\
Endoluminal conduit for treatment of type 2 diabetes & yes \\
$\quad$ (EndoBarrier) & \\
Two-component fibrin glue & no \\
Probe-based confocal laser microscopy & no \\
Gall duct-visualizing system & no \\
Fecal microbiome transfer (FMT) & no \\
Radiofrequency ablation of liver neoplasms & no \\
Fibrinogen/thrombin powder & no \\
Electrosimulation for gastroesophageal reflux disease treatment & yes \\
Over-the-scope clipping of bleedings, perforations, and fistulas & no \\
Radiofrequency ablation of the gall ducts & no \\
\hline
\end{tabular}

- Is the method new (i.e. in use no longer than 4 years at the time of first application) AND a real innovation?

- Does the method cause significant extra costs?

- Is the calculation plausible?

- Does the method lead to an imbalance in payment?

New

Every method/procedure that has been on the market for more than 4 years is automatically excluded from NUB. The 'innovation' clause is unclear, and the regulatory bodies are to have issued a binding definition by end of 2015 .

\section{Significant Extra Costs}

As already explained, to be significant, the costs of the complete treatment using a new procedure have to exceed or account for at least a significant proportion of the standard deviation of the respective DRG. 


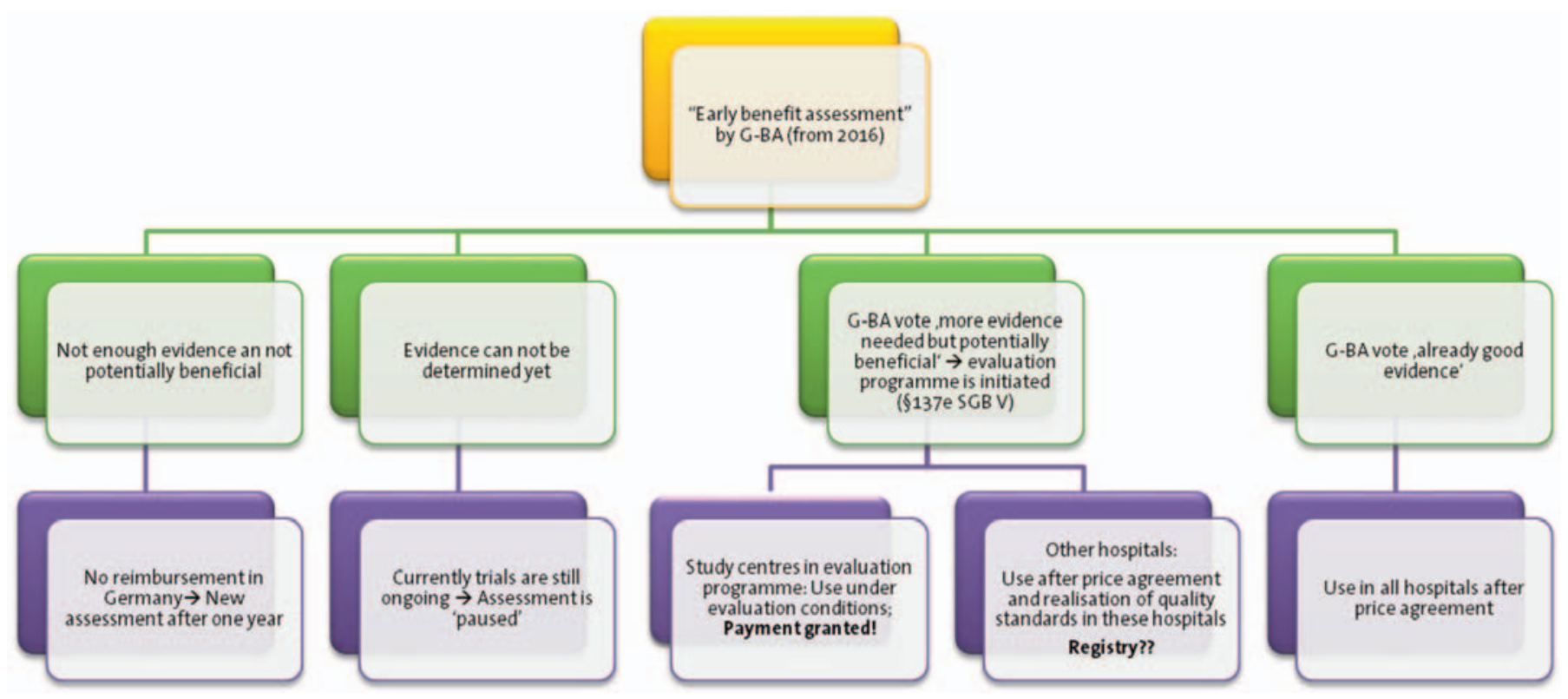

Fig. 2. Early benefit assessment by G-BA from 2016 on.

\section{Plausible Calculation}

Many procedures in endoscopy need capital equipment and disposables (like energy generators and ablation catheters). In most cases, similar equipment and disposables are already in use in the hospitals. If the costs for a disposable used with a capital equipment differ considerably (e.g. more than twice the expense) from the costs of existing disposables, InEK often mistrusts the calculation because the cost of the disposable eventually leads to the depreciation of the capital equipment, which the G-DRG system does not allow.

\section{Imbalance in Payment}

Costly new devices are integrated in the DRG system over time as explained in the 'Basic Principles' section. As the DRG system claims to provide average sufficient funding, costs that affect every hospital in the same way are not as critical as costs that disadvantage only a few hospitals. Thus, NUB applicants have to show that non-payment would lead to a disadvantage for the early adaptor hospitals, the so-called imbalance.

NUB payments are not automatically granted. Hospitals and insurances have to negotiate and agree a payment contract. Only then reimbursement is possible. This paper does not focus on the ins and outs of the negotiation process. However, 1 very common reason for debates in connection with NUB payments is the clinical benefit of a new procedure.

Until now, there has been no regular assessment of the clinical benefit of a new procedure. InEK basically examines the coverage and whether the procedure is really new. From 2016, all procedures that involve the use of a medical device with high invasiveness (class IIb and class III medical devices) will be assessed not only by InEK but also by the G-BA. This so-called 'early benefit assessment' targets the existing clinical evidence for the new device (fig. 2).
Detailed regulations will become available as soon as the Ministry of Health publishes the statutory regulations (December 2015) and G-BA updates its standard operating procedures (March 2016).

Aside from the detailed regulations, medical device manufacturers will face a major challenge for reimbursement of new methods in Germany. The assessment by G-BA has already been in use for pharmaceuticals since 2009, and the dossiers that have to be sent to G-BA are extensive documents containing a systematic literature research, detailed descriptions, list of serious adverse events, and so forth.

\section{Results from the Survey 'Daily Practice in NUB Payments"}

In 2015, Diller et al. [5] conducted a survey on how important NUB applications are for hospitals, whether NUB status 1 could be successfully negotiated, and what the role of medical societies should be.

The authors were able to demonstrate an increase in importance: In 2007, 2 years after NUB was established in Germany, the German Hospital Institute (Deutsches Krankenhausinstitut; DKI) found that $43.6 \%$ of all NUB applications got status 1, and 53\% were successfully negotiated by hospitals [6]. In 2015, the percentage of successful negotiations has increased. Therefore, more innovative products are passing the negotiation process due to the effort made by the hospitals, although the percentage of NUB payment from the overall budget is still $0.2-1 \%$ (table 4 ).

Medical controllers participating in the survey prefer NUB applications provided or supported by the respective medical societies. $81.3 \%$ of the respondents would like to use NUB application templates which have been published by societies. NUB is a hospital-specific application. However, most medical controllers per- 
Table 4. Percentage of successfully negotiated NUB with status 1

\begin{tabular}{lll}
\hline Survey (year) & NUB status 1, \% & $\begin{array}{l}\text { Successfully negotiated NUB } \\
\text { with status 1, \% }\end{array}$ \\
\hline DKI (2007) & 43.6 & 53 \\
NUB in der Praxis (2015) & 46 & 77 \\
\hline
\end{tabular}

ceive medical scientific societies as a quality gateway and trust the assessment/pre-selection of the societies.

\section{Framework for DRG Change Requests}

The typical steps involved in getting initial innovation funding after being CE marked is to apply for NUB and OPS in the first and second year of commercialization of a new method and associated medical devices or pharmaceuticals which are not covered by an existing DRG payment. The regulatory concepts ensure a bridge funding for the first 1-5 years after CE marking (fig. 3).

After the a OPS code has been established, treatments using the new method are coded in hospitals with a specific OPS. Due to this identifying coding system, hospitals are able to assign specific materials and staff costs to these patient cases. Hospitals participating in the annual DRG calculation send their case data to the InEK at the end of April of each year. InEk recalculates the relative weights of all DRGs based on these data. Due to this annual DRG recalculation, cost data for new methods first have an impact on the recalculation in year 3 . Therefore, increased values of relative weights are visible in the DRG catalogue of year 4. At this time, InEK either assigns methods receiving NUB payment to a certain DRG which covers the cost of the new method. InEK also can establish co-payment ('Zusatzentgelt' according to $\$ 9 \mathrm{KHEntgG}$ ) which is bound to the procedure code of the method. There are 2 types of co-payment: i) according to public standard rates; and ii) individually negotiated by the hospital.

Although InEK is examining DRG assignment and establishment of co-payment based on internal standard procedures for recalculation, it is recommended to anticipate these changes by using the formal possibility of sending a request for change to the InEK ('DRG-Vorschlagsverfahren' according to $\$ 17 \mathrm{~b}$ KHEntgG). These requests for change should be made by medical societies. Also, individual hospitals and professional associations (e.g. Bundesverband Medizintechnologie; BVMed) can avail of this option. Again the regulatory bodies explicitly name medical societies as an important player in order to involve external expert knowledge in the development of the G-DRG system [7].

\section{Generalized Pathway for New Procedures and the Role of Medical Scientific Societies}

Traditionally, the role of medical societies has been to provide clinical guidance to inventors of new methodologies. Initially, they gave advice for designing studies and helped to define clinical need and target populations in Germany. After this initial phase, socie-

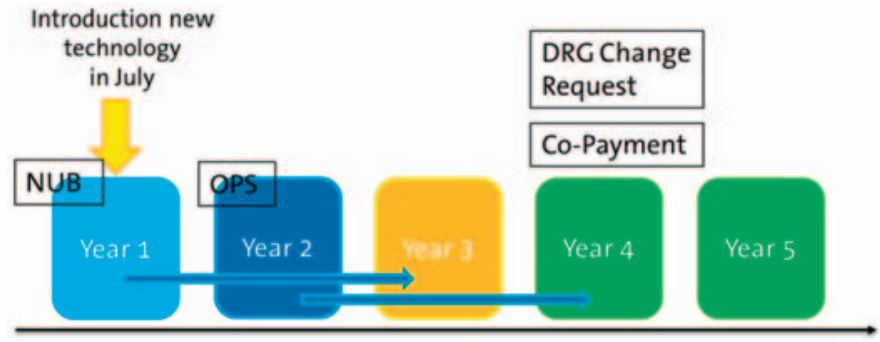

Fig. 3. Incorporation of new methods into the G-DRG system.

ties took responsibility for the incorporation of new methods into clinical guidelines [8] (fig. 4).

Additionally, regulatory bodies (e.g. DIMDI and InEK) expect continuous input and advice from medical societies, especially for the various formal applications (NUB, OPS, DRG change request) in conjunction with the innovation funding process and G-DRG development [7]. There is a clear reason why this input is needed. New methods can often only be understood by experts in this particular field. However, inventors and manufactures of the new methods have a conflict of interest. Therefore, medical societies serve as a quality gate for the regulatory bodies. Some societies have implemented expert groups for treatment-specific questions and a commission for medical-economic and classification-specific questions. Expert groups within the medical societies may advice on medical need, clinical pathways, evidence development, and cost-benefit questions. They are responsible for first statements, position papers, and incorporation of the new method into clinical guidelines. The commission for clinical-economic aspects may decide on supporting NUB and OPS applications and at a later stage will help to incorporate the new method into regular payment using DRG change requests. As mentioned earlier, the new early benefit assessment by the G-BA starting in 2016 will add a new challenge to hospitals and medical societies. For each NUB application, the submitting hospital has to provide a dossier which contains a systematic literature research, detailed descriptions, a list of serious adverse events, and so forth. Manufactures and hospitals will not be able to provide this without the help of the medical societies (fig. 5).

\section{Examples of Funding Pathways for 2 New Methods}

In the following section, we show the different funding pathways describing reimbursement development of the following endoscopic methods: 


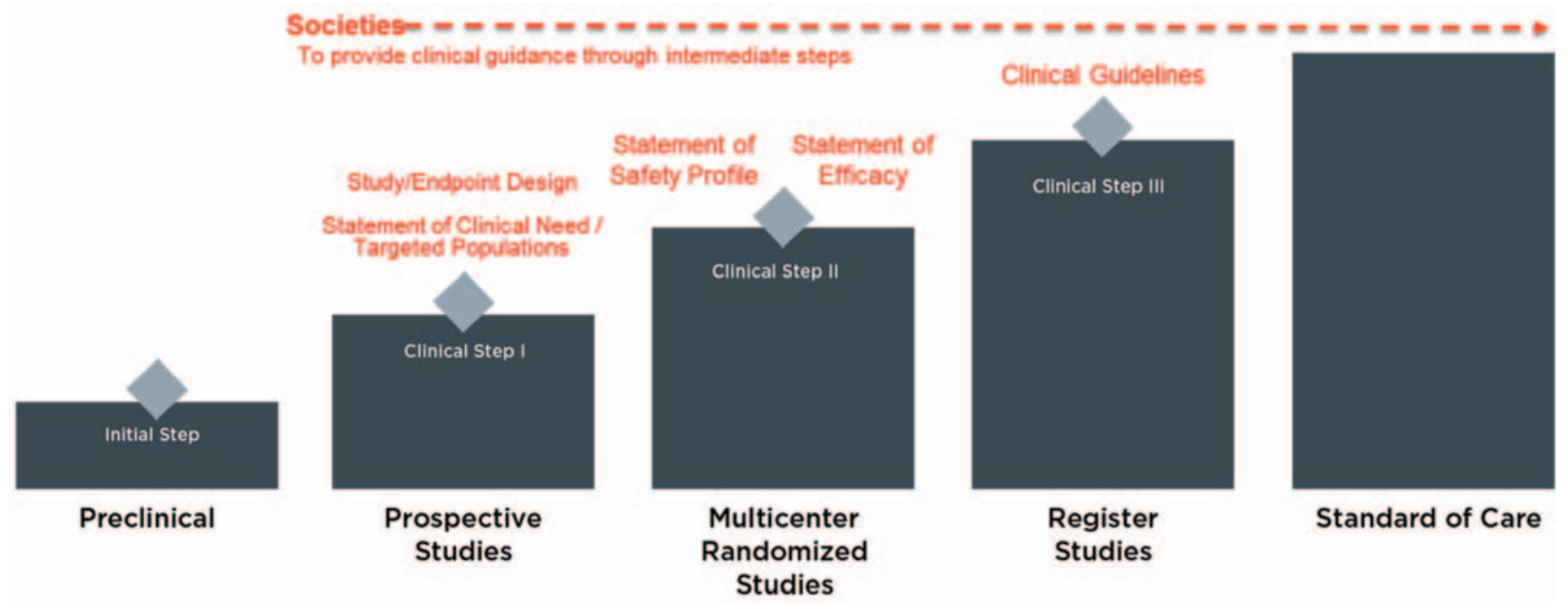

Fig. 4. Stepwise development of methods and society support.

Fig. 5. Support of incorporation into clinical guidelines and reimbursement development by medical societies.
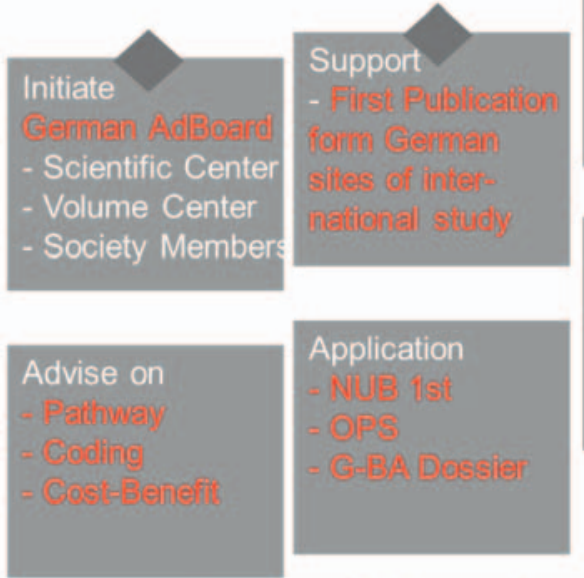

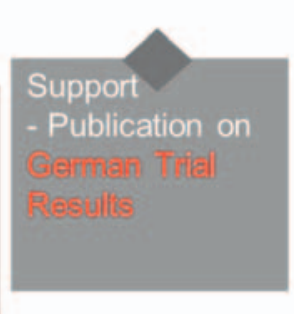

Reimbursement Development

- NUB 2nd

- Assure Coding
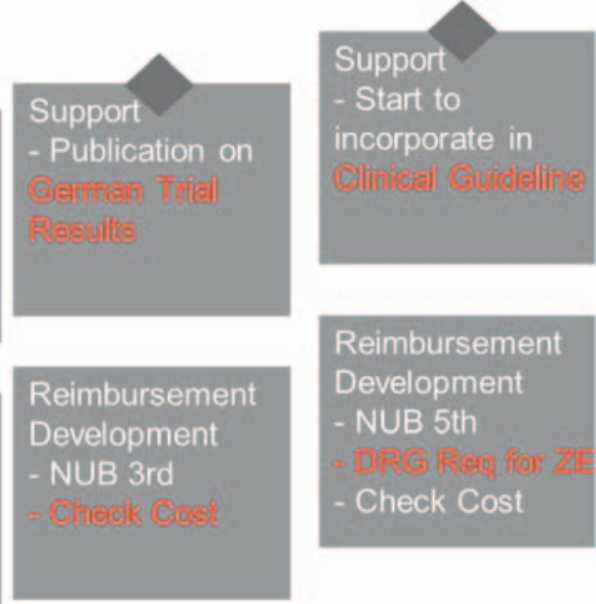

Reimbursement

Development

- NUB 5th

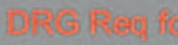

Check Cost

Source: Dr. Wilke GmbH - inspiring.health 2015

\section{year-1}

year+1

year+2

year +4

- Radiofrequency ablation for Barrett's esophagus (RFA Esophagus)

- EndoBarrier for treatment of type 2 diabetes with obesity (EndoBarrier for type 2 diabetes).

RFA Esophagus is coded as OPS2016 5-422.55. NUB was tried in 2006, but was declined by InEK (status 2). Although the additional costs exceeded the standard deviation of the initial DRG G46C, InEK stated that RFA is not a new method as it has been used for years in other application areas (table 5). Society and manufacturer did not agree, because the usage of an existing technical methodology in a new application area (esophagus) certainly meets the criterion of a new scientific concept. In 2011, hospitals in close cooperation with the DGVS re-applied for NUB; however, InEK once again rejected the application. This time, InEK argued that the reduction in the length of hospital stay reduces the additional cost, so the method is in fact already properly covered by the DRG G46C. The
DGVS subsequently changed its strategy and from 2012 applied every year for a shift from the initial G46C to a DRG which properly reimburses RFA Esophagus. InEK reacted in 2013 and assigned the procedure to G46B. Consistent surveillance of cost assignment for RFA Esophagus during the DGVS DRG project [9] led to a step-bystep increase in the relative weight of the G46B over time.

RFA Esophagus is a very good example for the above described pathway C, where NUB was rejected and the consistent support of the medical society led to more or less sufficient funding being granted. In parallel, RFA Esophagus has been integrated in the DGVS guideline for gastroesophageal reflux disease.

EndoBarrier for type 2 diabetes started with NUB status 2 in 2011 (table 5). It is one of the very rare examples where an NUB status 2 was changed to status 1 . EndoBarrier for type 2 diabetes is coded using (OPS2016: 5-469.q3). EndoBarrier for type 2 diabetes 
Table 5. NUB

\begin{tabular}{llll}
\hline Application & Status & Year & $\begin{array}{l}\text { Submitted by society / number } \\
\text { of hospitals if NUB }\end{array}$ \\
\hline $\begin{array}{l}\text { RFA Esophagus } \\
\text { OPS }\end{array}$ & accepted & 2009 & $\begin{array}{l}\text { DGVS } \\
\text { NUB }\end{array}$ \\
NUB & 2 & 2006 & 1 hospital \\
NUB & 2 & 2013 & 8 hospitals \\
NUB & 2 & 2013 & 8 hospitals \\
\hline EndoBarrier for type 2 diabetes & 2 & 2014 & 1 hospital \\
OPS & & & \\
NUB & accepted & 2014 & DGVS, DDG, DGAV, DGCH, BDC \\
NUB & 2 & 2011 & 7 hospitals \\
NUB & 2 & 2012 & 14 hospitals \\
NUB & 2 & 2013 & 36 hospitals \\
NUB & 2 & 2013 & 36 hospitals \\
NUB & 1 & 2014 & 29 hospitals \\
\hline
\end{tabular}

led in 2011 to $\mathrm{K} 60 \mathrm{E}$, which is a conservative DRG and does not cover the cost for the new treatment as it does not make provisions for implants, and the additional cost exceeded the standard deviation. The first NUB applications (2011-2012) did not properly address the criteria expected by InEK (see above). In 2013, hospitals used a revised NUB application which was supported by the DGVS. Also, the dialog with InEK established during the DGVS DRG project [9] was helpful for the change to status 1 .

EndoBarrier is a very good example of the merits of consistent support by the relevant societies. DGVS, German Society for General and Visceral Surgery (Deutsche Gesellschaft für Allgemein- und Viszeralchirurgie; DGAV), and German Diabetes Society (Deutsche Diabetes Gesellschaft; DDG) published in 2013 an initial statement (position paper) about this new method [10] and supervised the development of the method both in clinical and in economic terms. After a first unsuccessful trial run, EndoBarrier has been following pathway B since 2014 and is a classic example of a new method which falls into a conservative DRG where no endoscopic procedures are funded so far, but is still financed by NUB.

\section{Conclusion}

New procedures in endoscopy take time to be incorporated in the G-DRG system. A 5-year time frame is usually realistic and should be anticipated by gastroenterologists as well as by the device manufacturers. Depending on the extent of innovation and cost, several pathways are possible. Either the hospitals that want to introduce a new procedure or the manufacturers should undertake a thorough analysis before deciding to pursue one of the pathways. Data from our survey and feedback from other sources show that the support of the medical scientific societies is of utmost importance to establish new procedures in the German healthcare system.

\section{Disclosure Statement}

Dr. Michael-Holger Wilke and Markus Rathmayer are shareholders of inspiring-health, Dr. Wilke GmbH, München.

Authors receive consultancy honoraria from Deutsche Gesellschaft für Gastroenterologie, Verdauungs- und Stoffwechselerkrankungen (DGVS) in a DRG optimization project for Gastroenterology in Germany.

\section{References}

1 Statistisches Bundesamt: Gesundheit: Diagnosedaten der Patienten und Patientinnen in Krankenhäusern (einschl. Sterbe- und Stundenfälle). Fachserie 12, Reihe 6.2.1, 10/02/2015. www.destatis.de/DE/Publikationen Thematisch/Gesundheit/Krankenhaeuser/DiagnosedatenKrankenhaus2120621137004? blob= publicationFile (last accessed December 28, 2015).

2 Bundesministerium für Justiz und für Verbraucherschutz: Krankenhausentgeltgesetz - KHEntgG: $\$ 6$ Vereinbarung sonstiger Entgelte. www.gesetze-im-internet. de/khentgg/_6.html (last accessed December 28, 2015).

3 InEK GmbH: Aufstellung der Informationen nach $₫ 6$ Abs. 2 KHEntgG für 2015. Homepage InEK GmbH. www.g-drg.de/cms/G-DRG-System_2015/Neue_Untersuchungs-_und_Behandlungsmethoden_NUB/Aufstellung_der_Informationen_nach_6_Abs._2_KHEntgG_ fuer_2015 (last accessed December 28, 2015).
4 Deutsche Gesellschaft für Gastroenterologie: NUB: NUB Anträge vergangener Jahre. DGVS Homepage. www.dgvs.de/themen/drg/nub/ (last accessed December 28, 2015).

5 Diller I-M, Claudia Reiß C, Wilke M: NUB - Ist das Deutsche Gesundheitswesen innovationsfeindlich? Ergebnisse der aktuellen Umfrage 'NUB in der Praxis'. KU Gesundheitsmanagement 2015;2015:82-85.

6 Blum K, Offermanns M, Perner P: Neue Untersuchungs- und Behandlungsmethoden - nur wenige kommen durch. Krankenhaus Barometer kompakt, Umfrage 2007, pp. 7-8.

7 Bundesministerium für Justiz und für Verbraucherschutz: Krankenhausfinanzierungsgesetz - KHG: $\$ 17 \mathrm{~b}$ Einführung eines pauschalierenden Entgeltsystems für DRG-Krankenhäuser. www.gesetze-im-internet.de/ khg/_17b.html (last accessed December 28, 2015).
Malchau H: Introducing new technology: a stepwise algorithm. Spine 2000;25:285.

9 Rathmayer M, Heinlein W, Wilke M: GastroCostCh eck - Programm zur Prüfung von gastroenterologischendoskopischen Kostendaten (Frühjahr 2014). www. dgvs.de/themen/drg/prueftool-gastrocostcheck/ (last accessed December 28, 2015).

10 Siegel E, Kähler G, Schepp W: Positionspapier der Fachgesellschaften zur Anwendungsempfehlung der endoskopischen biliodigestiven Diversion in Deutschland - DDG/DGAV/DGVS. Z Gastroenterol 2014;52: 606-612. 